\title{
REFLOATING A SHIP USING HER OWN MEANS
}

\author{
VARSAMI, A[nastasia] E[lena]; CHIRCOR, M[ihael]; \\ POPESCU, C[orina] \& HANZU - PAZARA, R[adu]
}

\begin{abstract}
In this paper we research the conditions of a stranding casualty which are not completely determined in the beginning of and they are not fully defined during the salvage operation. Therefore the stranding condition and the environment are the principal sources of forces on a stranded ship. Our research emphasizes the fact that the operations for refloating a stranded ship are time-critical and environmental conditions may improve or worsen with time, but the condition of a stranded ship steadily deteriorates. The first manoeuvre taken into consideration by our research to be applied is represented by the attempt of refloating the ship by using the means present onboard (ship's own means of propulsions and ballast/de-ballast operations). These are the fastest manoeuvres available onboard and in the same time, they are the cheapest ones. The longer the ship remains in a stranded position, the higher are the possibilities for a ship to suffer severe damages and a pollution event to occur. In this paper, we are trying to analyse the possibility of refloating a ship by using her own means of propulsion, namely her main engine, in combination with ballasting and de-ballasting the stern tanks and the ones on the portside and starboard side. For this purpose, we have performed several simulations using TransasNavi Trainer 5000 Simulator.
\end{abstract}

Keywords: refloat, ship, stranding, casualty

\section{INTRODUCTION}

When talking about a ship that runs aground on a soft seabed we have to take into consideration the principal energy absorbing mechanisms which stop the ship and these are normally:

- Deformation of the seabed.

- Friction between seabed and hull.

- Change of potential energy of the ship and the surrounding water.

- Deformation of the hull.

- Hydrodynamic damping.

The ship, with her main characteristics and dimensions is presented below, a bulk-carrier, Figure 1, fully loaded and she runs aground on a soft muddy bottom, where the water depth is 15 metres.

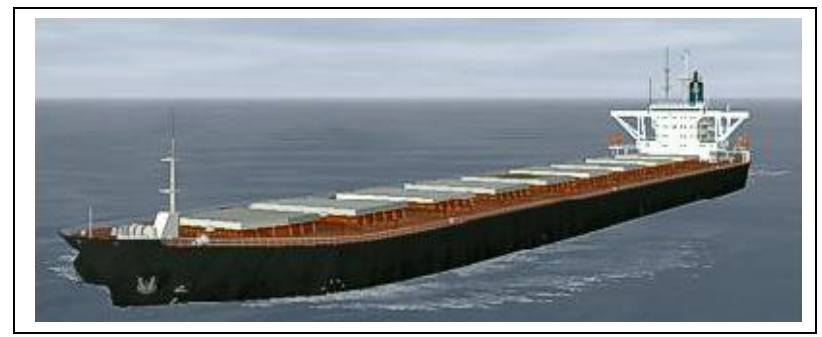

Fig. 1.The simulated bulk-carrier

\begin{tabular}{|c|c|}
\hline Type of engine & Diesel $1 \times 14720 \mathrm{~kW}$ \\
\hline Type of ship & Bulk-carrier \\
\hline Bowthruster & No \\
\hline Sternthruster & No \\
\hline Type of propeller & Fixed pitch propeller \\
\hline Deadweight & 14.6 Knots \\
\hline Maximum speed & $290 \mathrm{~m}$ \\
\hline Maximum Length & $46 \mathrm{~m}$ \\
\hline Maximum Beam & $17.7 \mathrm{~m}$ \\
\hline Bow draft & $18.7 \mathrm{~m}$ \\
\hline Stern draft &
\end{tabular}

Tab. 1. The main characteristics and dimensions of the simulated ship

During the simulations, we have selected a series of pre-set parameters, like:

- bow/stern drafts

- transversal/longitudinal speeds

- vertical and longitudinal forces

- rolling moment, pitching moment, lateral moment

and we have been following their variation for different situations of refloating attempts.

In the following paragraphs, we are going to present in details the actions taken to refloat the ship, attempts made only by using the ship's own means. It must be also taken into consideration that around the casualty there is no tide, wind and/or surface current.

\section{REFLOATING STRANDED SHIPS}

There are several different methods for refloating stranded ships and these imply the following actions:

- Moving the ship to water deep enough to float it at the draft corresponding to its weight.

- Deepening the water around the casualty.

- Reducing the required draft at the grounded portion by removing weight, lifting, or altering trim.

In practice, there is always a combination of these actions that is normally used. In most cases, the stranded ship is lightened until the required freeing force is less than the available tractive forces, and then pulled into deeper water. It is often necessary to remove many tons of cargo, stores, or floodwater.

\subsection{Moving the Casualty}

In order to move a casualty it must be taken into consideration that the force required to move that 
particular stranded ship over its strand is the sum of the forces required to:

- Overcome friction between the ship and seafloor.

- Move loose seafloor material that may be pushed ahead of the ship.

- Break or crush obstructions or impalements, such as rock outcroppings, coral heads, etc.

- Overcome suction on soft bottoms.

Friction is a function of ground reaction as modified by other factors, such as the coefficient of friction of the bottom, the area of the hull in contact with the bottom, and the casualty's list and trim. Freeing force is reduced by decreasing the effects of these factors, as well as by decreasing ground reaction.

\subsection{Reducing Water Depth}

The reasons for trying to increase the water depth under and around a casualty are:

- To obtain sufficient water depth to refloat the vessel.

- To reduce ground reaction by increasing buoyancy.

- To free one end of a vessel to allow it to be pivoted by other methods.

Water depth inside small coves or estuaries can be increased by closing the entrance with sheet-steel piles or cofferdams. In some navigable rivers and canals, water level can be controlled to some extent by lock gates and dams - it may be possible to raise water level by increasing flow past upstream dams. On very soft soils, it may be possible to increase the ship's weight, by flooding or other means, so that she settles more deeply into the seafloor. After she has settled, the excess weight can be removed to allow her to float free. More commonly, water depth around a casualty is increased by removing ground from under it. Ground removal is accomplished by scouring or dredging soft bottoms, or by blasting hard bottoms.

\subsection{Temporary Reduction}

Dynamic friction is almost always less than the static friction between two objects. If freeing force can be reduced long enough for the pulling system to start the ship moving, it can usually be kept moving. Swells increase the buoyancy of the stranded ship and decrease the ground reaction as they pass. High seas or heavy swells running during a retraction decrease the pulling force required to refloat the ship. If the pulling force is enough to start the ship moving at the top of a swell when ground reaction is lowest, the coefficient of friction is lowered instantly to the dynamic level. The dynamic coefficient of friction may be low enough that freeing force stays less than pulling force after ground reaction increases again, and the ship keeps moving. When there are no natural swells, ships passing parallel to the beach at high speed create swells that act like the natural swell. Destroyers running a long racetrack pattern as close to the refloating operation as safety permits are ideal for this purpose. Jacking reduces freeing force by changing the nature of the ground reaction, rather than reducing it.
By taking up part of the ship's weight on the jacks, the amount of weight bearing on the high friction interface between the ship's bottom and seabed is decreased. The jacks are rigged on long spuds that can pivot at their bases, allowing the casualty to be moved when the friction force is sufficiently reduced. Jacks are placed symmetrically about the estimated position of the centre of ground reaction and are secured with a retrieving line led to the deck. The jacks are raised to their maximum lift at the beginning of a pull. When the ship moves, the jacks will topple and must be reset for the next operation. Once the stranded ship is moving, it is often possible to keep it moving against the lower dynamic coefficient of friction, even if the ground reaction increases when the jacks trip. If not, the casualty is refloated by moving it seaward in a series of short steps. For jacking to be successful, the seafloor must be hard enough, or must be reinforced, to support the jacking forces. On rock seafloors, concrete rubble-filled beds or heavy timbers topped by steel plate are adequate foundations.

On sediment seafloors, plate or timber mats are used to spread the load until the unit pressure is less than the bearing capacity of the soil. Crushed coral, stone, shell, or gravel can be laid in to increase soil bearing strength. Similarly, the hull of the ship must be protected from the jacking forces. If these forces are not spread out along the hull, they will cause local damage at the point of application and may even rupture the hull. Steel welding or heavy steel angles welded to the hull and padded with timbers are suitable jacking pads. The load is transmitted to the ship structure by shear stress in the welds and side plating.

\subsection{Explosives}

Explosive measures to reduce freeing force include:

- Judicious use of small charges to deepen the water around the casualty and cut channels through hard bottoms (explosive dredging).

- Explosively cutting or pulverizing coral or rock outcroppings that are impaling the casualty or blocking its retraction.

- Using small charges along the length of the casualty to cause vibration and fluid behaviour in the seafloor under the casualty.

- Detonating moderate charges several hundred feet from the casualty to generate artificial swells to momentarily increase buoyancy.

Use of explosives requires skill and experience to avoid damaging the casualty.

\section{SIMULATION}

The simulation presents a combination of refloating methods: using the main engine in different levels and directions of speed with ballasting/de-ballasting the ship in order to reduce the bow draft and thus the pressure exerted by the ship on the sea bottom. 
In the first simulation $\mathrm{S}-1$, Figure 2 , the attempt to refloat the ship only by using the main engine is performed, the ship swings to portside/starboard to a certain angle, about the pivot point, but she does not manage to refloat herself. Previous positions of the ship towards forward can be noticed, because the main engine has been used on 'ahead' and then 'astern' positions. The motion vector 'astern' has the maximum value, a value that corresponds to the 'full astern' level of speed.

It must be mentioned that in real cases, when the ship is grounded with part of the bow on the bottom and the stern is free to move and thus floating and the propeller is totally submerged (in our case the bow is grounded for about $90-100$ metres of the ship's total length), when the main engine is used 'astern' at a high level of revolutions per minute, the stern rises and this makes the bow 'go deeper' into the mud, and this does not help in any way in our particular case.

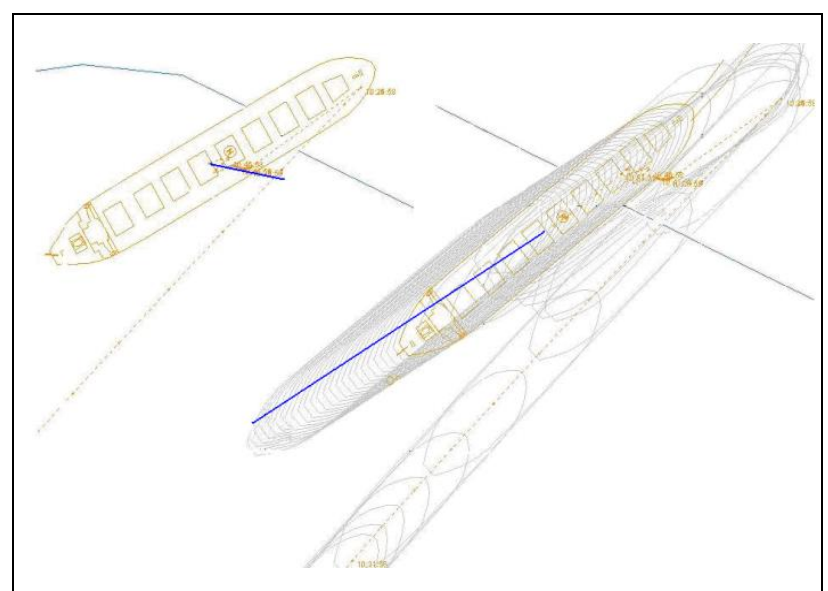

Fig. 2. S-1 The attempt to refloat the ship by using the main engine at 'full speed astern'

There are high variations of the lateral motion moment and of the longitudinal force. The lateral force on the propeller still has small variations (approximately $20 \%$ of the maximum value). The rolling and pitching moments are zero throughout the whole period of simulation.

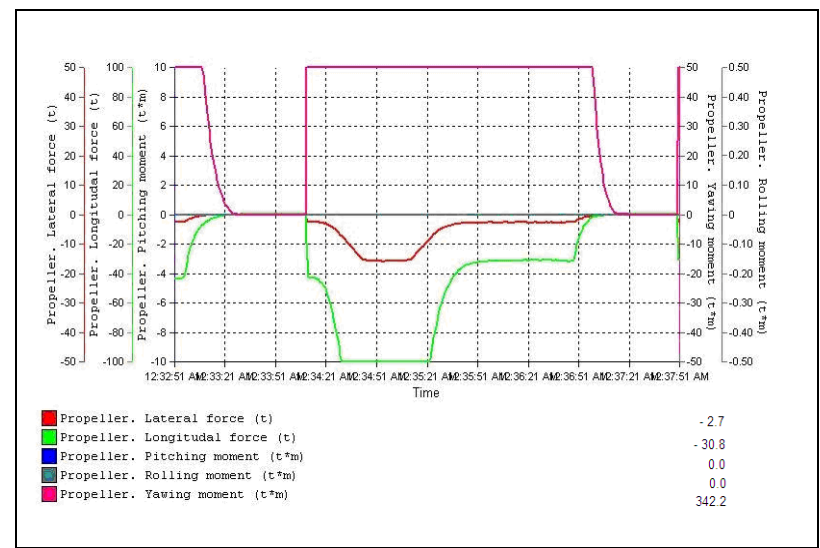

Fig. 3. S-2 Parameters' variation during the refloating attempt

In S-2, Figure 3, we have caught the moments for the refloating attempt by using the main engine 'ahead astern' in combination with ballasting the aft tanks and fast de-ballasting. Because the ship is loaded, there is no possibility to fully ballast the tanks.

The next action was to try to ballast the tanks in one board with the scope of listing the ship but the full loaded condition of the ship did not allow this, as in the case of a proper ballasting the aft tanks. However, in S-6, Figure 7 , it can be observed a slight list to portside during the ballasting/de-ballasting process.

The only parameter that still varies is the lateral motion moment ( $\mathrm{S}-4$, Figure 5) and the longitudinal force varies with small values.

From the image, it can be seen that in the moment of stopping the simulation, the value of the parameters is almost everywhere zero.

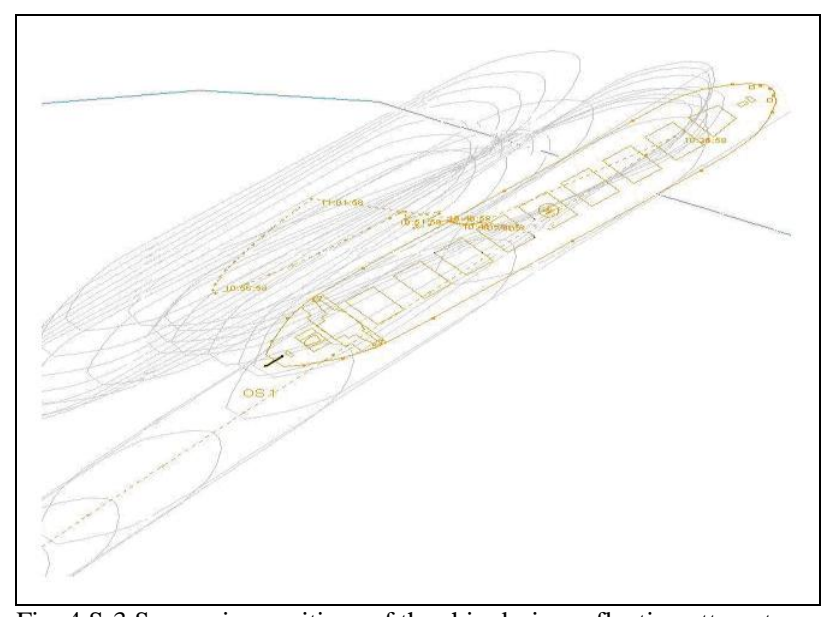

Fig. 4.S-3 Successive positions of the ship during refloating attempt

In $\mathrm{S}-5$, Figure 6, it can be easily seen the ship's motion about the pivot point, and that the ship has a tendency 'to get out' (a slight motion backwards) but, because the engine is stopped or reduced, the ship 'goes back' to her past position.

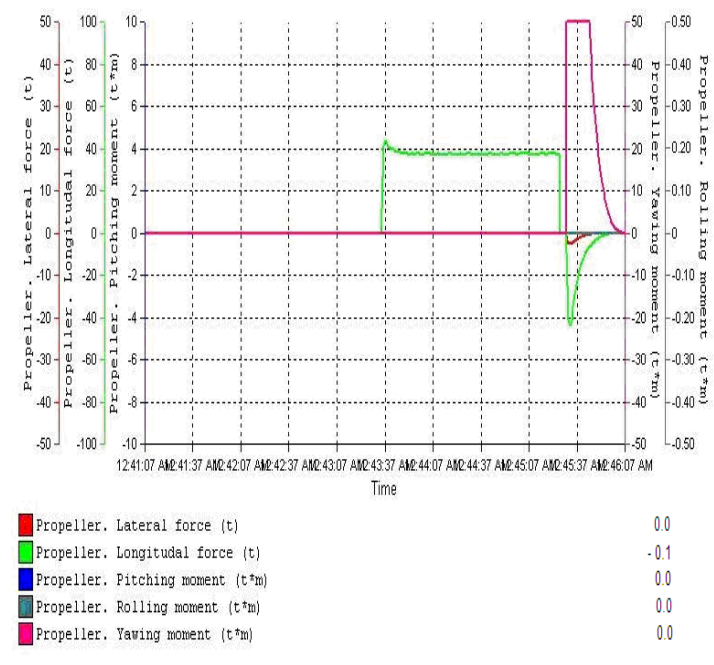

Fig. 5.S-4 Variation of the selected parameters (for the propeller) 


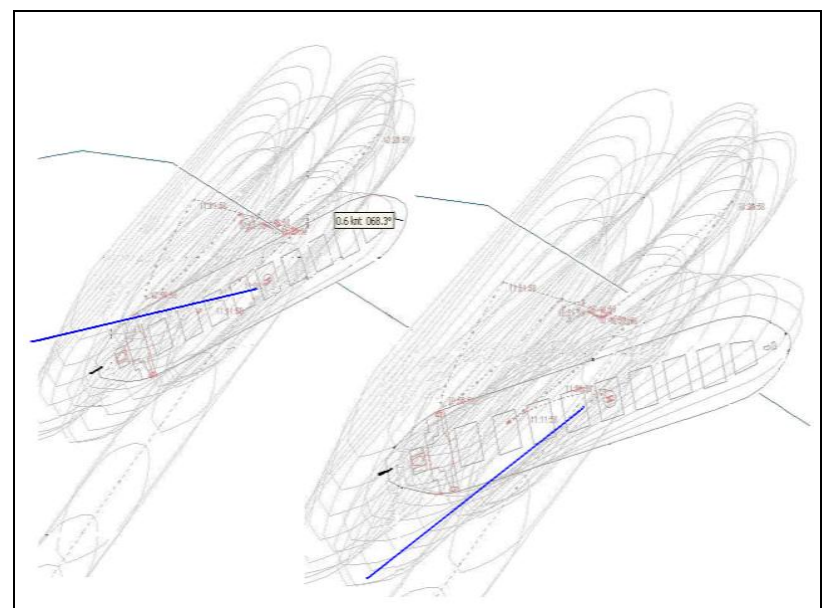

Fig. 6. S-5 The apparent motion 'astern' of the ship when using the engine 'full astern'

S-6, Figure 7, shows the successive positions of the ship during the refloating attempt by using the combined method with the ship's main engine and ballasting the aft tanks and the ones in portside and starboard.

Despite all efforts, the ship does not manage to refloat herself and in this situation the only available solution is to move the cargo from the forward tanks to another ship.

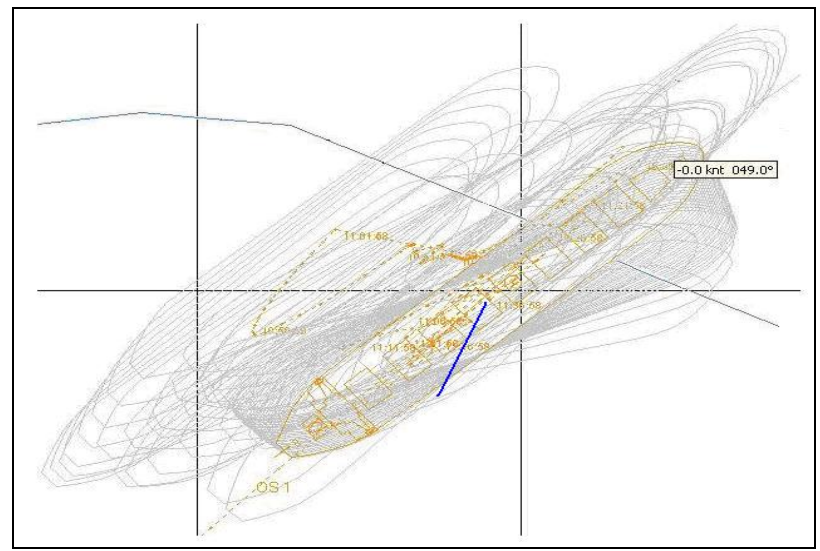

Fig. 7. S-6 Successive positions of the ship during refloating attempts by using the main engine 'ahead - astern' at different levels of speed

Due to the nature of the sea bottom, namely mud, the ship doesn't manage to refloat by using her own means of propulsion. The ship cannot manoeuvre astern because the pivot point or the gyration point (the point from where the bow and the stern can be seen gyrating with the same angular speed) changed its' position (at the stern of the number three hold as it can be seen in the picture) and thus it remains fixed in a position relatively close to $1 / 3$ of the ship's length measured from the bow. It can be easily seen that approximately $100 \mathrm{~m}$ of the ship's length measured from the bow is 'stuck' in the mud, and the thickness of the bed is at least $1.5-2$ metres if taking into account only the difference of draft.

Using the main engine at 'full speed astern', initially shows the fact that the ship's refloating could be possible but the motion vector with its' direction astern (although it has a certain value that indicates the ship's movement and its' possible refloating) indicates a lateral motion, a motion of gyration of the ship about the pivot point.

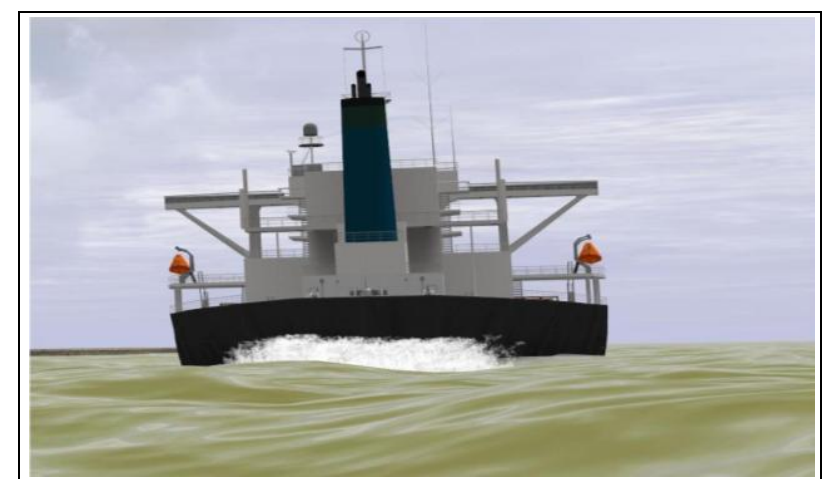

Fig. 8. S - 7 The ship's image with the engine ' full astern'

\section{CONCLUSION}

As a result from the simulation we observe that the ship cannot manoeuvre astern because the pivot point or the gyration point changed its' position (at the stern of the number three hold) and thus it remains fixed in a position relatively close to $1 / 3$ of the ship's length measured from the bow. It can be easily seen that approximately $100 \mathrm{~m}$ of the ship's length measured from the bow is 'stuck' in the mud, and the thickness of the bed is at least $1.5-2$ metres if taking into account only the difference of draft.

Therefore, using the main engine at 'full speed astern', initially shows the fact that the ship's refloating could be possible but the motion vector with its' direction astern (although it has a certain value that indicates the ship's movement and its' possible refloating) indicates a lateral motion, a motion of gyration of the ship about the pivot point.

The method used to refloat the ship, namely using her own means of propulsion and ballasting the aft tanks and the ones in portside and starboard side, did not manage to free the ship. Future research will take into consideration to move the cargo from the forward tanks to another ship and eventually to ask for external help. All these further actions imply extra costs that must be supported by the owner and they are almost every time the last options taken into consideration.

\section{REFERENCES}

[1] Barsan, E., Hanzu, R., Iordanoaia, F., Batrinca, G. \& Arsenie, P. (2010), Utilizarea Simulatoarelor in Procesul de Instruire, Nautica Publishing House, ISBN 978·606·8105·36·9, Constanta, Romania

[2] Barsan, E. \& Muntean, C. (2010). Combined Complex Maritime Simulation Scenarios for Reducing Maritime Accidents Caused by Human Error, Proceedings of the WSEAS 3rd International Conference on Maritime and Naval Science and Engineering, 3$5^{\text {th }}$ September, Constanta, Romania, ISSN 1792-4707 88, ISBN978-960-474-222-6, pp. 88-93, Published by WSEAS Press, Athens Greece

[3] Varsami, A. \& Chircor, M. (2011). Stranded Ships and their Salvage. Constanta Maritime University Annals, Vol. 12, No. 15 , December 2011, pp. 105-109, ISSN 1582-3601

[4] Varsami, A., Popescu, C., Dumitrache, C., Hanzu, R., Chircor, M. \& Acomi, N. (2011). The Influence of Grounding Events on Maritime Industry, Proceedings of the $22^{\text {nd }}$ International DAAAM Symposium, 23-26 ${ }^{\text {th }}$ November, Vienna, Austria, ISSN 17269679, ISBN 978-3-901509-83-4, pp. 0591-0592, Published by DAAAM International, Vienna, Austria 